Gonçalves, P.M.R. Entre novas matizes e permanências: a emergência do Turismo e os simbolismos do Morro da Conceição. Revista Brasileira de Ecoturismo, São Paulo, v.6, n.1, jan/abr-2013, pp.29-40.

\title{
Entre novas matizes e permanências: a emergência do turismo e os simbolismos do Morro da Conceição
}

\author{
Among new nuances and permanences: the emergence of tourism and the \\ symbolism of the Morro da Conceição (RJ, Brazil)
}

Paulo Maurício Rangel Gonçalves

\begin{abstract}
RESUMO
O presente artigo visa analisar os processos decorridos no Morro da Conceição ao longo de sua trajetória geográfica recente, de maneira a compreender as vicissitudes desta área na atual geografia do centro do Rio de Janeiro. A fim de atingir tal objetivo, esta pesquisa abarca, de maneira sucinta, os processos atuais que ocorrem nesta área do centro da cidade. Em seguida, são investigadas as funções que são delineadas no Morro da Conceição hodiernamente, sob o foco de empreendimentos e ações que vicejam em seu perímetro. Problematizamos os impactos da turistificação que ocorre neste lugar, sob a égide de investimentos infraestruturais, na esteira de futuros grandes eventos, a ocorrer na cidade em futuro próximo. São abordadas e analisadas, sob o prisma da geografia humanística, as relações estabelecidas entre os múltiplos agentes sociais que habitam e/ou transitam neste espaço, assim como o tipo de relação que estes indivíduos têm com o seu solo, seu lugar, fontes de identidade e simbolismos diversos para os grupos sociais citadinos.
\end{abstract}

PALAVRAS-CHAVE: Lugar. Turistificação. Morro da Conceição. Rio de Janeiro.

\begin{abstract}
The present article aims to analyze the processes elapsed at Morro da Conceição over its recent geographical trajectory, in order to understand the vicissitudes of this area in the current geography of the center of Rio de Janeiro. In order to achieve this goal, this research includes, briefly, the current processes occur in this area of the city center. Next, we investigate the functions that are outlined in Morro da Conceição nowadays, from the focus of projects and actions that grow on the perimeter. We discuss the impacts of the touristification that occur in this place, that under the aegis of infrastructural investments, coming on the roll of futures major events that will occur in the city in a coming future. They are addressed and analyzed from the perspective of humanistic geography, the relationships established between multiple social agents who live and/or walk in this area, as well as the type of relationship these individuals have with their land, their place, source of identity and several symbolisms to townsman groups.
\end{abstract}

KEYWORDS: Place. Touristification. Morro da Conceição. Rio de Janeiro. 


\section{Introdução}

Em tempos de mudanças cada vez mais rápidas neste alvorecer de século XXI, torna-se de suma importância o olhar espacial. Os fixos e os fluxos ornamentam e conferem luminosidade a múltiplos espaços, em lógicas tão variadas quanto os agentes que implementam estes deslocamentos e/ou se põem em movimento. Inserido em um mundo de viscerais transformações e movimentações, para o geógrafo Yi-Fu Tuan, "a geografia é o estudo da Terra como o lar das pessoas" (TUAN,1991, p.89). Em contraposição a este cenário de intensas movimentações, tomaremos o lar como uma pausa, como uma longa e lenta respiração em um mundo de fugacidades ${ }^{1}$. Ao ter como guia as ideias de Tuan, no decorrer deste estudo geográfico objetivaremos realçar o homem, com seu mundo de significados, dramas, teias sociais e felicidades, em um espaço em mutação.

De acordo com Cosgrove (1998), somos geógrafos a todo momento, estando a geografia em toda parte. Nesta curiosidade geográfica, a multiplicidade de lugares e a explosão de centralidades em um único espaço urbano sempre foram objeto de fascínio (MELLO, 2002), assim como as espacialidades de grupos sociais distintos, portadores de diferenciados lares/lugares. Tais injunções engendram uma heterogeneidade muito característica da cosmopolita metrópole carioca. Neste contexto, as transformações pelas quais a cidade do Rio de Janeiro passou ao longo da organização de seu espaço ganham bastante relevo. A cidade, outrora reconhecida como o "túmulo dos estrangeiros" (SEVCENKO, 1984, p.48), hoje ostenta a alcunha de "Cidade Maravilhosa". É instigante imaginar como e porque ocorreram estas transformações, quem foram seus atores, e se existiram processos contra-hegemônicos. Todas estas indagações podem vir à tona quando observamos, principalmente, o centro da cidade do Rio de Janeiro.

Não obstante, algumas localidades nos convidam a ter um olhar especial pelo seu poder de resistência. Ao caminharmos pelo centro da cidade do Rio, nos confrontamos com um lugar central, uma área core para os negócios, gestão e movimentos que emanam e são irradiados da e pela cidade. A rapidez dos fluxos, ornamentados pelas torres, sedes de grandes empresas, destoa bastante da contiguidade espacial da área. De um lado, observa-se a verticalização do núcleo central com edificações de diversos patamares e, nas circunvizinhanças, o domínio de uma área assobradada repleta de funções "pouco nobres", tais como bares, mercearias, residências unifamiliares e plurifamiliares. Nesse caso, faço uma alusão direta à zona portuária da cidade, especificamente ao Morro da Conceição, que pode ser entendida como uma porção espacial diferenciada do seu entorno. Embora sejam logradouros relativamente próximos, há um contraste enorme entre a agitação da Avenida Rio Branco e a quase letargia da Ladeira do João Homem; nos mapeamentos sócio-espaciais, uma pertence ao centro e outra ao bairro da Saúde, incluído na periferia da área central do Rio de Janeiro (RABHA, 1984).

O Morro da Conceição, localizado no bairro da Saúde, é um dos remanescentes dos quatro morros que delimitavam o sítio original da cidade (São Bento, Santo 
Antônio, Castelo e Morro da Conceição) e o único que, de alguma forma, permaneceu preservado. Situado junto ao coração financeiro da cidade, o Morro da Conceição é reservado aos olhos mais distraídos, se escondendo entre os altos edifícios, antigos armazéns e o Elevado da Perimetral. Sendo uma área residencial desde o século XVIII, resistiu ás intenções de sucessivos planos urbanísticos que desestimularam a moradia no Centro, se mantendo em uma espécie de congelamento para o olhar mais desavisado. Transpor seus acessos é experienciar uma temporalidade e um cotidiano pretéritos que se manifestam sob o tempo e espaço presentes; é se inserir em um outro ritmo, em uma outra atmosfera. Subir suas meandrantes ladeiras dizem respeito a vivenciar um contraste inevitável ao sair da pulsação nervosa do centro de negócios, ou da batida silenciosa da paisagem acinzentada de um porto hoje em transformação (SIGAUD; MADUREIRA, 2000).

O presente artigo tem como propósito explorar a dinâmica turistificação de um lugar da área central do Rio de Janeiro, qual seja: o Morro da Conceição. Ao ter como referência as palavras de Claval, ao mesmo tempo, o texto busca "estudar as relações complexas que se desenvolvem entre os homens e os ambientes onde eles vivem" (CLAVAL, 2004, p.21). Sob este prisma, o aproveitamento de fragmentos que lancem luzes sobre as complexidades do relacionamento do homem com a Terra é obrigatório. Logo, a problematização central deste artigo reside em enxergar como o habitante do Morro da Conceição está vivenciando o Morro e os seus lugares hodiernamente, um período em que o Morro da Conceição está em grande evidência. O aporte da geografia humanística é extremamente importante nesta leitura, por procurar nos dramas, alegrias, entusiasmos e decepções ocorridos no mundo vivido, a essência das relações do homem com o espaço, traduzindo assim a alma dos lugares. Afinado com este princípio fenomenológico, o geógrafo espanhol Nogué Y Font traz à baila a importância da subjetividade dos indivíduos para esta análise, ao afirmar que "as relações de tipo sensorial, afetiva, estética e simbólica, que o indivíduo mantém com a paisagem que lhe rodeia, são mais importantes do que parecem ao simples oIhar" (NOGUE Y FONT, 1992, p.88) ${ }^{2}$. Ao ter em mente que "cada pessoa é rodeada de camadas concêntricas de espaço vivido" (BUTTIMER, 1982, p.178), nos cumpre investigar o simbolismo dos lugares no Morro da Conceição para os diferentes indivíduos insiders e outsiders, em seus "mosaicos de lugares" (BUTTIMER, 1982, p.177) particulares.

Utilizando-se do inventário intelectual do geógrafo estadunidente David Lowenthal, Werther Holzer fornece parte do substrato metodológico humanístico a ser abarcado na análise. Para Holzer,

a geografia é a ciência que mais se aproxima da incorporação sem mediações dos elementos da vida cotidiana, que devem ser considerados em suas particularidades a partir da inclusão dos mundos vividos pessoais como um dado concreto da disciplina (HOLZER, 1999b, p.155). 
Neste contexto, o espaço deve ser visto como um contínuo dinâmico, recheado de nuances, fragrâncias, simbolismos e identidades, que deve ser apreendido de maneira holística, não devendo ser analisado sem o elemento humano. Logo, o Morro da Conceição não é apenas um conjunto de fortaleza, palácio, fachadas portuguesas históricas e ladeiras íngremes, é também - e principalmente - a sua população.

\section{A turistificação do Morro da Conceição}

Desde o final do século passado, na esteira de um processo de turistificação que atinge algumas localidades do centro do Rio, o Morro da Conceição teve sua visitação incrementada. O casario de fachadas históricas, ainda conservado em alguns de seus pontos, é descoberto e batizado pela mídia cult da Cidade Maravilhosa. Ateliês e bares são abertos, convidando cada vez mais outsiders a vivenciarem o espaço do Morro. Em um dos sopés do Morro da Conceição, na mítica Pedra do Sal, é verificada uma super-utilização dos fixos locais, situação esta que suscita opiniões conflitantes dos insiders, ou seja, dos próprios moradores da área ${ }^{3}$. Segundo Cosgrove, "o local é um lugar simbólico, onde muitas culturas se encontram e talvez entrem em conflito" (COSGROVE, 1998, p.93). Em coadunação com esta ideia, até quando esta popularização do Morro da Conceição não se transformaria em um transtorno para a população que nele habita e tem seu espaço de vivência enquanto um lugar?

No que tange a questão espacial, o conceito de lugar, que é de suma importância para o estudo geográfico, norteará as investigações e inquietações aqui propostas. Em diálogo com este viés de análise, Lukermann afirma que o estudo do lugar é a matéria-prima da geografia (LUKERMANN, 1964, apud HOLZER, 1999a, p.69). Destarte, nos cumpre efetuar uma distinção entre dois conceitos-chave, que são dois dos pilares da geografia contemporânea: o espaço e o lugar. Diferentemente do espaço, que é aberto, livre, amplo, vulnerável, causador de ansiedades; o lugar é fechado, íntimo, organizado, pleno de ternura e empatia (MELLO,1997). O lugar seria assim um "mundo de significado organizado" (TUAN, 1983, p.198), frente à amplitude do continuum que é o espaço. Em complementaridade a estas ideias, acrescenta Ballesteros (1992, p.11):

\footnotetext{
...centro de significados, condição da própria experiencia, foco de vinculação emocional para os seres humanos, contexto para nossas ações e fonte da nossa identidade, o conceito de lugar se opõe ao geométrico espaço abstrato do neopositivismo e, diferenciado-se deste, está cheio de significados e valores, que são inseparáveis da experiência dos que nele habitam, de seus pensamentos e sentimentos"4.
}

A partir desta premissa, denotando a necessidade da não banalização do conceito de lugar, visto que é um imponente conceito em geografia - principalmente na vertente humanística - neste momento atual buscamos enxergar os lugares e as pessoas que os integram. Neste período específico, em que os espaços do Morro e arredores são muito frequentados por turistas, oriundos de múltiplas localidades. Sob esta 
perspectiva, embora não tenhamos infraestrutura hoteleira na localidade para pernoite dos turistas, a mesma tem sido muito procurada por empresas e grupos para fornecer "lazeres urbanos" (RODRIGUES, 2001, p.89) alternativos para turistas e visitantes da cidade do Rio de Janeiro.

Seguindo a atual tendência de valorização da cultura local e do sentido de "pertencimento", antigos espaços degradados de grandes cidades, principalmente áreas portuárias, estão sendo reabilitados e revividos como lócus de lazer (Rodrigues, 2001, p.92). Neste quadro, a Prefeitura da cidade do Rio de Janeiro ${ }^{5}$, por intermédio do Projeto Porto Maravilha, concluiu uma previsão de investimentos na área de cerca de $R \$ 8$ milhões (oito milhões de reais), apenas para a recuperação das históricas ladeiras do Morro da Conceição. Melhorias no calçamento e iluminação, além de abertura de vias, pretendem aprimorar a qualidade de vida dos cerca de dois mil habitantes do Morro da Conceição, e com isto atraindo também mais visitantes para a área em foco.

$\mathrm{Na}$ esteira deste processo de melhorias infraestruturais que podem vir a alavancar a turistificação do Morro da Conceição, o Projeto Mauá revela seu pioneirismo. Criado por quatro artistas em 2002, o projeto consistia na utilização de residências como ateliês para a exposição de obras de arte de artistas da cidade e de fora. Com o passar dos anos, parceiros foram incorporados a esta empreitada, como a Fundação Sesi e a própria Prefeitura da cidade do Rio de Janeiro. Na divulgação de suas obras, ocorre também uma divulgação dos espaços do Morro, acarretando, inclusive a criação de bares-restaurantes de relativo requinte, face à presença de turistas na área.

Neste diapasão, empreendimentos turísticos florescem no Morro, que se torna palco e roteiro de atividades turísticas. Inúmeros grupos privados hoje implementam caminhadas pelas ruas e vielas do Morro; em trajetos os quais em tempos passados eram monopolizados por trabalhos de campo acadêmicos. A criação do Projeto Palácios do Rio, por iniciativa de uma instituição pública de Ensino Superior da cidade do Rio de Janeiro, é um destes exemplos e denota este fato. Com o intuito de implementar o desenvolvimento local sustentável e a valorização do patrimônio histórico e cultural da cidade, visitas guiadas são promovidas, conferindo oportunidades para guias de turismo e lucratividade para comerciantes locais. Nesta seara, é importante realizar uma análise do discurso turístico presente em um folder do grupo (ver Figura 1). Cumpre realçar o quão louvável é a atitude de divulgar a cultura e patrimônio do Morro, no entanto a propaganda utilizada pode conferir noções incompletas acerca da realidade a ser exposta (TOMAZZONI, 2006). Ao propagandear "Visitas guiadas ao Palácio, Fortaleza e Morro da Conceição", externaliza-se o Palácio e a Fortaleza da Conceição do próprio Morro da Conceição, quando estes estão inseridos no Morro, conferindo a este um papel complementar, ao menos por uma via de interpretação do discurso lido / propagandeado. Na verdade, sob nossa análise, tanto o Palácio como a Fortaleza fazem parte de uma miríade de lugares que constituem o Morro da Conceição, não devendo, por conta disto, serem vistos de maneira isolada. 


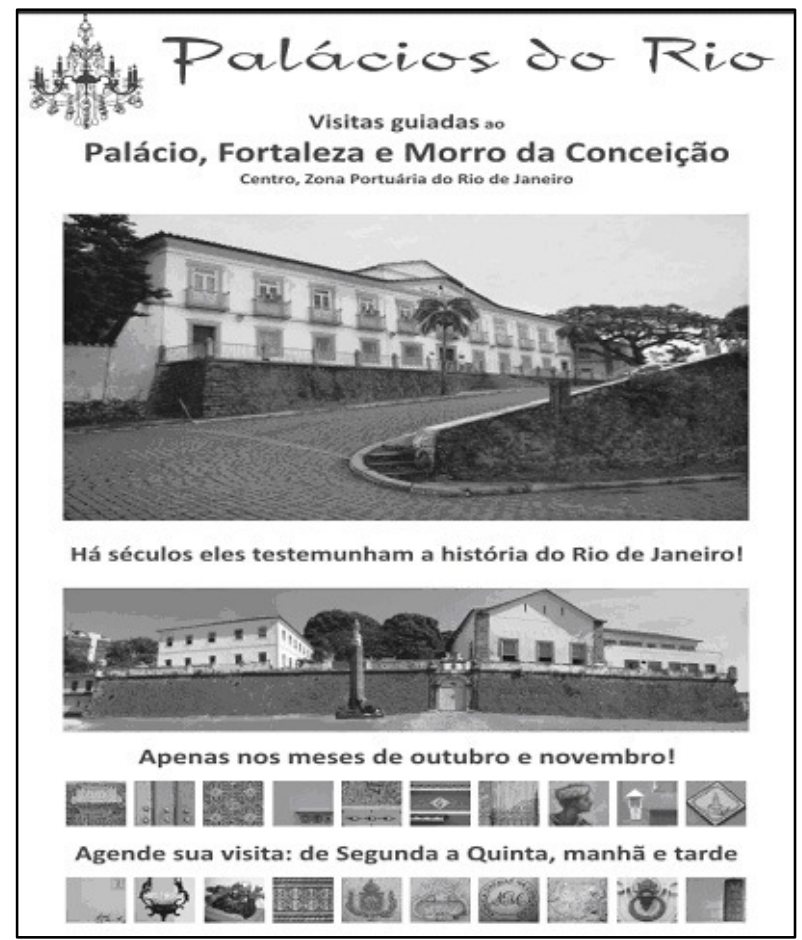

Figura 1: Folder do Projeto Palácios do Rio. Fonte: http://palaciosdorio.blogspot.com/, 2011.

Figure 1: Folder of Project Palácios do Rio. Source: http://palaciosdorio.blogspot.com/, 2011.

\section{O descortinar dos lugares}

No tocante a desfraldar e a indicar atividades turísticas em um dos espaços mais característicos do Rio antigo nesta pós-modernidade, nos cumpre apresentar algumas faces do Morro da Conceição; onde lugares se fundem com experiências pessoais e interpessoais. É instigante visualizar a vivacidade e a criatividade dos sujeitos humanos no espaço, e perceber como "os ambientes humanos são extensões do nosso próprio corpo" (BERQUE, 1999, apud CLAVAL, 2004, p.51). A praça Major Valô, que se situa à frente da Fortaleza da Conceição, recebeu esta toponímia em 1929, em homenagem a um austríaco que modernizou o serviço geográfico militar (GERSON, 2000, p.144-145). No entanto, para a população local, esta praça é vernacularmente conhecida como "praça da santinha" (em função da presença da estátua de N. S. da Conceição), demonstrando simpatia e o carinho com esta porção do espaço, que se desvela como um lugar para os que nutrem por ela um sentimento topofílico ${ }^{6}$. A praça serve de palco não para a entrada de armamentos, como fora projetada originalmente, mas para reuniões populares do Grêmio Recreativo Banda da Conceição e do bloco Escravos da Mauá, que, em mágicos Balés do Lugar ${ }^{7}$, congregam a população do Morro e do "asfalto" em efusivas, sacolejantes e sonoras reuniões (ver Figuras 2a e 2b). A polivocalidade das formas do lugar denotam a pluralidade de significados e de interpretações distintas que enriquecem o cenário em tela (CORREA, 2007). 

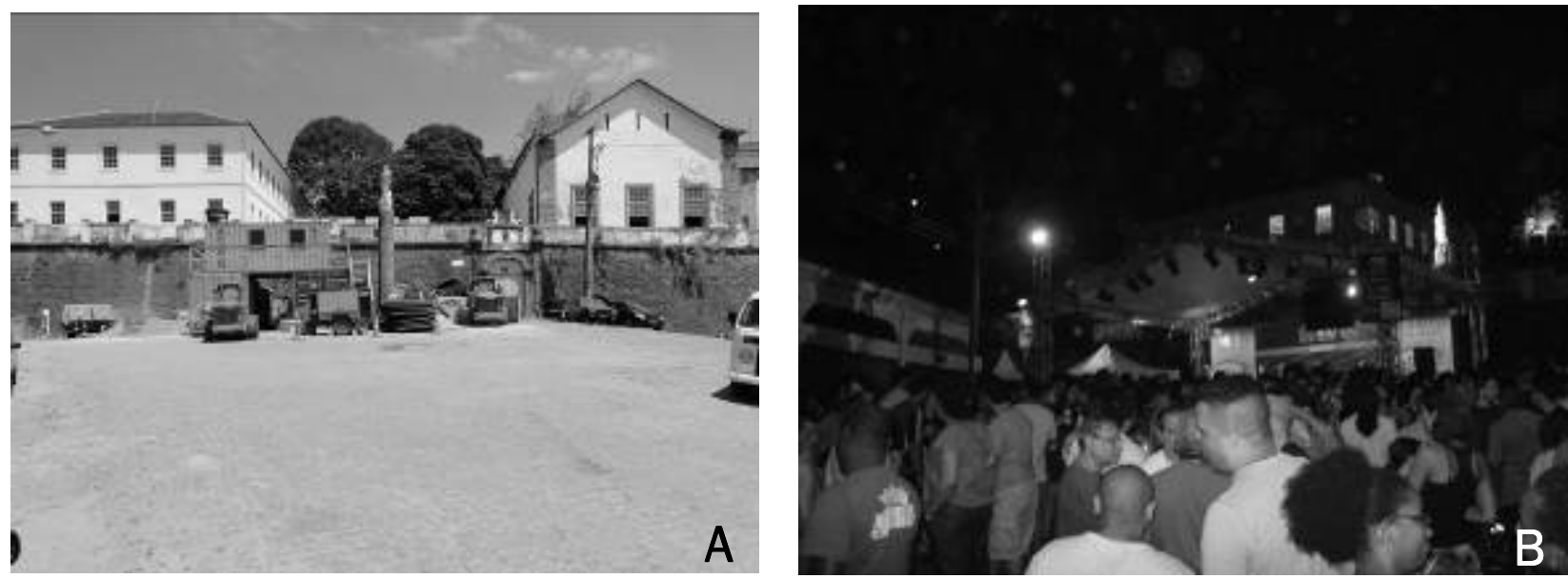

Figura 2: Fotos que representam momentos distintos da Praça Major Valô. Na foto 2a não verificamos a mesma efervescência da foto $2 b$, quando a Praça da santinha é tomada por centenas de pessoas para assistir ao show dos Escravos da Mauá. Fonte: Arquivo do autor, 2012 e 2011, respectivamente.

Figure 2: Pictures that represent different moments of the Praça Major Valô. In the second photo did not check the same effervescence photo $2 \mathrm{~b}$, when the little saint Square is taken by hundreds of people to watch the show from the Escravos da Mauá. Source: Archive author, 2012 and 2011, respectively.

Seguindo esta linha de raciocínio, a Pedra do Sal, um grande rochedo de gnaisse facoidal, em um dos sopés do Morro da Conceição, antigamente chamada de "quebra-bunda", era bastante utilizada como caminho para carga e descarga de navios no porto. Embora permaneça na toponímia, não mais é descarregado sal, mas sim sambas e choros, em melodiosas reuniões, no oficial Largo João da Baiana. Embora polarize fluxos de distintos lugares para a os lúdicos e festivos eventos sonoros, a incrementação da visitação da Pedra do Sal pode também ser uma tormenta para os moradores do Morro. A mesma escadaria que foi talhada em rocha é utilizada não apenas pelos que ovacionam os tão bem cantados sambas de outrora, mas também pelos trabalhadores que voltam às suas casas no alto do Morro da Conceição. Este choque de territorialidades em micro escala não pode passar despercebido de nossa análise. Em uma escala que mistura conceitos, sob a luz do sol a escadaria é um espaço para uns e um lugar para outros, enquanto que nas noites de samba, a escadaria tem seu sentido metamorfoseado, pois se transforma em lugar para uns e espaço para outros (ver Figuras 3a e 3b). O fenômeno da centralidade assume nuances no referido ponto geográfico, pleno de simbolismo e memória arraigada.

Em suma, as vivências e diferentes trajetórias geográficas da população que reside e frequenta o Morro da Conceição enriquecem bastante o recorte em tela. $A$ geografia da cordialidade dos moradores locais para com os que visitam os pontos do Morro é de impressionar e, por conta disto, se torna extremamente relevante para nossa análise. Ser "chamado pelo nome" assim que se conhece um morador local é algo habitual, assim como o respeito e o cumprimento terno, que são sempre repetidos, criando uma atmosfera de familiaridade mesmo para os que nunca antes ali estiveram. Em uma conversa informal com uma moradora, esta afirma: "Moro há mais de 30 anos no mesmo número e acho que vou morrer ali. Aqui eu criei três filhos. Adoro 

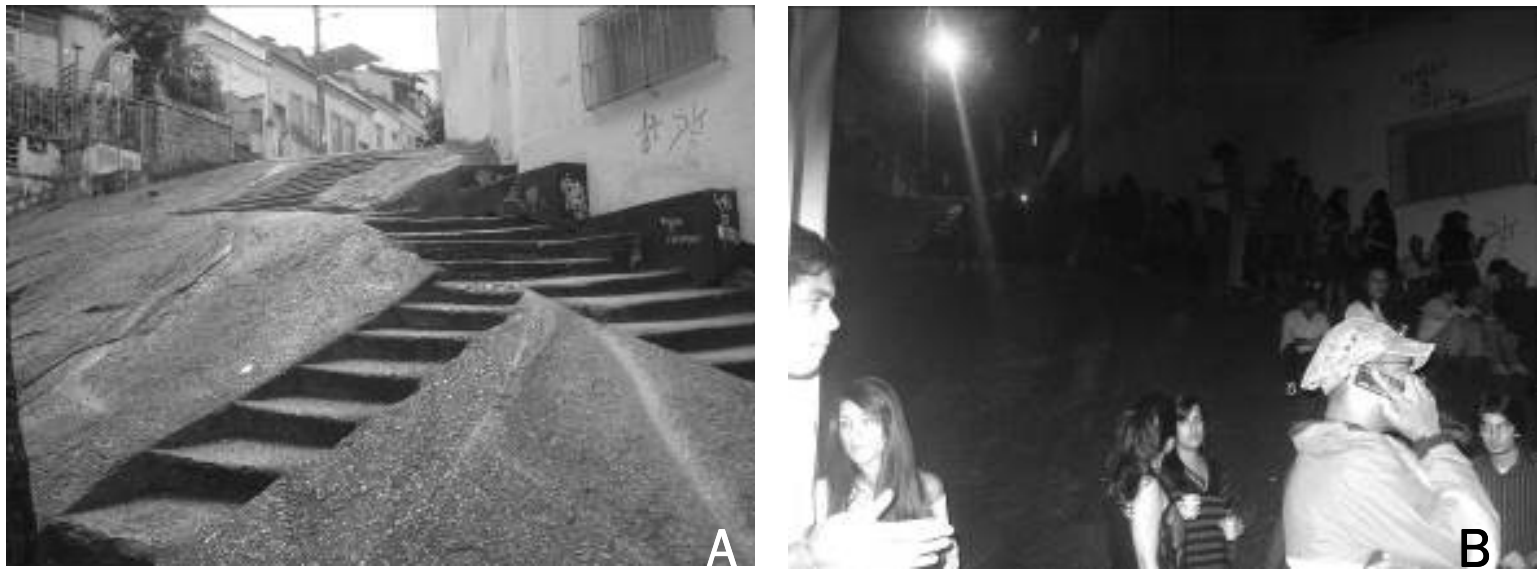

Figura 3: As fotos retratam dois momentos da escadaria da Pedra do Sal, uma durante o dia e outra durante uma noite de samba na Pedra do Sal. E interessante notar a presença acentuada de pessoas sentadas na escadaria (2a) na segunda foto (2b), fato que pode vir a gerar conflitos com os moradores do Morro da Conceição. Fonte: Arquivo do autor, 2010 e 2011, respectivamente.

Figure 3: The photos depict two moments of the staircase of the Pedra do Sal, one during the day and another during a night of Samba at Pedra do Sal is interesting to note the strong presence of people sitting on the steps (2a) in the second photo $(2 \mathrm{~b})$, a fact that might lead to conflict with residents of Morro da Conceição. Source: Archive author, 2010 and 2011, respectively.

este lugar'. Segundo as concepções de David Lowenthal, todo ser humano é um geógrafo informal (LOWENTHAL, 1985) e com sua geograficidade, a moradora de maneira afetuosa se refere ao seu nicho de histórias, presente e futuro como o seu lugar, uma arena para ela repleta de simbolismo. Da mesma maneira, em uma tarde ensolarada de outubro de 2011, um jovem estudante quando voltava do colégio para casa pondera: "Nasci no Morro e não pretendo sair não, todos os meus amigos moram por aqui". De acordo com as elucubrações de Douglas Pocock, "Nosso lugar de nascimento deixa uma marca na maneira como percebemos o mundo" (POCOCK, 1981, p.339) ${ }^{8}$. Desta forma, nos cumpre realçar os fortes laços de pertencimento com o torrão natal e com o grupo social de convivência. Isto é de tal ordem evidente que falando de seu mundo vivido, o jovem usa de maneira livre e afetuosa o vocábulo "morro", por vezes pejorativamente utilizado no Rio de Janeiro, transpassando uma visão etnocêntrica negativa, ao mencionar o Morro da Conceição. Ainda segundo Pocock, "o lugar, então, contém nossas raízes, nosso único ponto de referência" (POCOCK, 1981, p.339) ${ }^{9}$ ou seja, a topofílica ligação destes indivíduos com o seu solo é de notória expressão, matéria-prima para o entendimento de suas relações com o mundo.

Nesta lógica, fascinados com a atmosfera do Morro da Conceição, com a bela arquitetura portuguesa ainda conservada na fachada das casas e com a hospitalidade dos moradores, pessoas de várias procedências (ou outsiders) tendem a voltar, fazendo desta visita um itinerário de vivacidade e nostalgia. Em meio a este contexto, em um fragmento colhido na elevação em destaque, consideremos as ideias a seguir expostas: "As coisas aqui parecem ter um poder de permanência maior. Embora não 
seja daqui, me sinto muito identificado, muito familiarizado", afirmara um jovem da Zona Norte da cidade. Em suma, o Morro da Conceição é um lugar - ou um conjunto de lugares - que pulsa $(\mathrm{m})$ fortemente, junto ao coração da Cidade Maravilhosa.

\section{Conclusão}

A atividade turística vem conferindo novas movimentações e luminosidades ao Morro da Conceição. Geografias pretéritas convivem com geografias hodiernas, sob o tilintar de eventos que inserem cada vez mais o Morro no mainstream carioca. Estaria surgindo uma nova Santa Tereza ${ }^{10}$ no seio da zona portuária? Acreditamos ser ainda cedo para tal afirmativa. Na verdade, as pessoas estão buscando novas referências para repetir a vida de relações e o glamour exibidos pelo citado bairro. No entanto, para a população do Morro da Conceição, face este processo de turistificação, paira o risco de perder o principal elemento de qualidade de vida na área, ou seja, o caráter bucólico, de perfil interiorano, de paz e tranquilidade. Estas são amenas características que podem ser substituídas pela agitação de restaurantes voltados para os visitantes, gerando grande tráfego de veículos, poluição sonora e atmosférica, além de problemas de segurança típicos dessas áreas. Acrescenta-se a tal realidade o fato do avanço da especulação imobiliária poder vir a mudar drasticamente a realidade do Morro da Conceição. O aumento do preço dos imóveis poder vir a forçar uma diáspora de moradores, já que o índice de domicílios alugados no Morro é muito elevado (cerca de $48 \%$ do total) ${ }^{11}$. Em consonância com as ideias de Edward Relph, "as pessoas são os seus lugares e o lugar é o seu povo" (RELPH, 1976, p.34) ${ }^{12}$, ou seja, em termos conceituais e de experiência, por se revelarem imbricados, não são facilmente diferenciáveis. Logo, sabendo que um indivíduo não é distinto de seu lugar, ele é esse lugar (RELPH, 1976), conclui-se que a perda populacional pode vir a transformar o recorte espacial em tela.

Ao partilharmos da concepção que "o turismo e o lazer devem ser abordados nas questões relativas a qualidade de vida urbana, tendo como pano de fundo a conservação e a melhoria do meio ambiente" (RODRIGUES, 2001, p.93) nos cumpre indagar e problematizar se existirão significativas mudanças no ambiente e quais seriam as implicações dessas mudanças no modo de vida, no cotidiano dos indivíduos em sua relação identitária com seus lares/lugares. Ou seja, em um período de toporreabilitação do Morro da Conceição, espaços, lugares e "deslugares" (MELLO, 1997) são postos no manifesto, podendo tanto suscitar a topofilia como o topocídio para os indivíduos insiders e outsiders no Morro da Conceição.

À guisa de conclusão, em uma das entrevistas livres recentemente realizadas (novembro de 2011), ao conversar sobre as significações do Morro da Conceição com um morador, residente há mais de 40 anos no local, o mesmo comentou: "o Morro da Conceição parece pequeno, mas é muito grande". Nesta concepção, procurando aprofundamento na subjetividade da resposta, convém fazermos um paralelo entre a cartografia e o depoimento. Se cartograficamente o Morro da Conceição possui reduzidas proporções, para este indivíduo trata-se de um universo explendoroso, detentor de um relicário de memórias, presente e futuro. O seu mundo, ou melhor, o seu uni- 
verso dotado de uma expressiva grandiosidade, tão extenso quanto o seu mosaico de experiências no lugar. Lugar que traz em seu bojo relações identitárias que podem tanto se retrair como se intensificar, face o atual processo de turistificação do Morro da Conceição.

\section{Referências Bibliográficas}

BALLESTEROS, A.G. Las aportaciones de la geografia humanística. In: BALLESTEROS, A. (org.). Geografia y humanismo. Barcelona: Oikos - tau, 1992.

BUTTIMER, Anne. Apreendendo o dinamismo do mundo vivido. In: CHRISTOFOLETTI, A. (Org.).Perspectivas da Geografia. São Paulo: Difel, 1982.

CLAVAL, P. A Paisagem dos Geógrafos. In: CORRÊA, R.L.;ROSENDAHL, Z.(org) Paisagem, Textos e Identidades. Rio de Janeiro: EdUERJ, 2004.

CORREA, R.L. Formas Simbólicas e Espaço: Algumas Considerações. Revista Geographia, Ano IX, № 17, Niterói: EdUFF, 2007.

COSGRove, D. A Geografia Está em Toda Parte. Paisagem e Simbolismo na Geografia Humana. In: CORRÊA, R.L.; ROSENDAHL, Z.(org) Paisagem, Tempo e Cultura. Rio de Janeiro: EdUERJ, 1998.

GERSON, B. História das ruas do Rio: e da sua liderança na história política do Brasil, 5. ed., Rio de Janeiro: Lacerda, 2000.

GONÇALVES, P.M.R.. Passados presentes e futuros possíveis: inércia, diferenciação de áreas e toporreabilitação na Rua Sacadura Cabral e na Pedra do Sal. Monografia apresentada ao Departamento de geografia da UERJ em janeiro de 2010.

HOLZER, W. O lugar na geografia humanista. Revista Território. Rio de Janeiro. Ano IV. n.7. p. 67-78. jul./dez. 1999a.

HOLZER, W. Paisagem, Imaginário e Identidade: Alternativas para o Estudo Geográfico. In: ROSENDAHL, Z.; CORRÊA, R.L. (org). Manifestações da Cultura no Espaço. Rio de Janeiro: EdUERJ, 1999b.

LOWENTHAL, D. Geografia, experiência e imaginação: em direção a uma epistemologia geográfica. In: CHRISTOFOLETTI, A. (ed.). Perspectiva da geografia. São Paulo: Difel, p. 103-141. 1985.

MELLO, J.B.F. Espaço, lugar e "Deslugar". Redes. Rio de Janeiro, v.1, n.2, p. 93-107, 1997.

MELLO, J.B.F. Explosões de Centralidade na Cidade do Rio de Janeiro. In: MARAFON, G.J.; RIBEIRO, M.F. (Orgs.). Estudos de Geografia Fluminense. Rio de Janeiro: Editora Infobook, 2002.

NOGUE Y FONT, J. El paisaje existencial de cinco grupos de experiencia ambiental. Ensaio metodológico. In: BALLESTEROS, A. (orgs.) Geografía y Humanismo. Barcelona: Oikos-tau. p. 87-96. 1992. 
POCOCK, D.C.D. Place and the novelist. Transactions of the Institute of British Geographers N.S. p. 337-247, 1981.

RABHA, N. M. C. E. Cristalização e resistência no Centro do Rio de Janeiro. Dissertação (Mestrado em Geografia) - Universidade Federal do Rio de Janeiro, 1984.

RELPH, E. Place and placelessness. London: Pion, 1976.

RODRIGUES, A.B. Geografia do turismo: novos desafios. In: TRIGO, L.G.G. (Org.). Turismo: Como aprender, como ensinar. 2. ed. São Paulo: SENAC, p. 87-122. 2001.

SEAMON, D. Body-subject, time-space routines and place-ballets. In: BUTTIMER, A.; SEAMON, D. The human experience of space and place. New York: St. Martin's Press, 1980.

SEVCENKO, N. A revolta da Vacina - Mentes insanas em Corpos Rebeldes. Rio de Janeiro. Editora Brasiliense - Coleção Tudo é História no 89, 1984.

SIGAUD, M.F.; MADUREIRA, C.M. Morro da Conceição: da memória o futuro. Rio de Janeiro: Sextante/IPP, 2000.

TOMAZZONI, E.L. Análise do discurso turístico da serra gaúcha. Em Questão, Porto Alegre, v.12, n.2, p. 339-365, jun./dez. 2006.

TUAN, Yi-Fu. A view of geography. Geographical review, v.81. pp 99-107.1991.

TUAN, Yi-Fu. Espaço e Lugar. São Paulo: Difel, 1983.

TUAN, Yi-Fu. Topofilia: um estudo da percepção, atitudes e valores do meio ambiente. São Paulo: Difel, 1980.

\section{Outras fontes referenciadas}

Jornal O Globo, seção Centro, edição de 26 de agosto de 2011.

http://palaciosdorio.blogspot.com/, consultado em 10 de outubro de 2011, às 16:40.

\section{Notas:}

Para Tuan, o lar "é a velha casa, o velho bairro, a velha cidade ou a pátria" (TUAN, 1983. p.3). Ao nosso ver, são fortes fontes de permanência, que podem ser entendidos como pausas nestas movimentações.

2 Tradução do original: "las relaciones de tipo sensorial, afectivo, estético y simbólico, que el indivíduo mantene com elpaisaje que le rodea, son más importantes de lo que parecen a simple vista" (NOGUE Y FONT, 1992, p.88).

${ }^{3}$ Ver GONÇALVES, P.M.R. Passados presentes e futuros possíveis: inércia, diferenciação de áreas e toporreabilitação na Rua Sacadura Cabral e na Pedra do Sal. Monografia (especialização em Políticas Territoriais no Estado do Rio de Janeiro), Instituto de Geografia, universidade do estado do rio de Janeiro, Rio de Janeiro, 2010. 
${ }^{4}$ Tradução do original: "Centro de significados, condición de la própria experiência, foco de vinculación emocional para los seres numanos, contexto para nuestras acciones y fuente de nuestra identidad, el concepto de lugar se opone al geometrizado espacio abstracto del neopositivismo $y$, a diferencia de este, está lleno de significados y valores, que son inseparables de la experiencia de quienes lo habitan, de sus pensamientos y sentimientos" (BALLESTEROS, 1992, p.11).

${ }^{5}$ Ver: http://www.portomaravilhario.com.br/projetos/morro-da-conceicao/

${ }^{6}$ Para o geógrafo Yi-Fu Tuan, "a palavra "topofilia" é um neologismo, útil quando pode ser definida em sentido amplo, incluindo todos os laços afetivos dos seres humanos com o meio ambiente material[...] mais permanentes e mais difíceis de expressar, são os sentimentos que temos para com um lugar, por ser o lar, o lócus de reminiscências e o meio de se ganhar a vida" (TUAN, 1980. p.107).

${ }^{7}$ Conceito de David Seamom (1980), que traduz a interação completa entre população e lugar, com trajetórias e geografias que se complementam.

${ }^{8}$ Tradução do original: "Our birthplace leaves a mark in determining the way we perceive the world" (POCOCK, 1981. p.339).

${ }^{9}$ Tradução do original: "Place, then, contains our roots, our unique point of reference" (POCOCK, 1981, p.339).

${ }^{10}$ Ver o jornal O Globo, seção Centro, 26 de agosto de 2011.

${ }^{11}$ Sobre estes índices, ver SIGAUD, M.F.; MADUREIRA, C.M., 2000, p.45.

${ }^{12}$ Tradução do original: "People are their place and place is its people" (RELPH, 1976, p.34).

Paulo Maurício Rangel Gonçalves: Universidade do Estado do Rio de Janeiro, Rio de Janeiro, RJ, Brasil.

Email: paulomauriciorangel@gmail.com

Link para currículo Lattes: http://lattes.cnpq.br/0822150843775734

Data de submissão: 08 de julho de 2012

Data de recebimento de correções: 20 de novembro de 2012

Data do aceite: 20 de novembro de 2012

Avaliado anonimamente 